\title{
What are the assessment instruments chosen by elementary school Teachers and what are the reasons to choose them?
}

\section{Quais instrumentos de avaliação os professores do ensino fundamental escolhem usar e por que esses?}

\section{¿qué instrumentos de evaluación eligen utilizar los maestros de educación primaria y por que?}

\author{
Heike Schmitz $^{1}$ (D) Themyres Gabriele Santos Almeida $^{1}$ iD, Beatriz Noia Souza ${ }^{1}$ iD \\ ${ }^{1}$ Universidade Federal de Sergipe, São Cristóvão, Sergipe, Brasil. \\ Autor correspondente: \\ Beatriz Noia Souza \\ Email: beatriz_noia@outlook.com \\ Como citar: Schmitz, H., Almeida, T. G. S., \& Souza, B. N. (2021). What are the assessment instruments chosen by \\ elementary school Teachers and what are the reasons to choose them? Revista Tempos e Espaços em Educação, \\ 14(33), e14289. http://dx.doi.org/10.20952/revtee.v14i33.14289
}

\begin{abstract}
To understand the teachers' choice of learning assessment instruments in Elementary School (Ensino Fundamental I), a field research was conducted in two schools of the Municipal Education System of Aracaju (Sergipe). After an analysis of the Political-Pedagogical Project of each school, the teachers' perceptions and opinions were verified through questionnaires and open interviews with focus groups, as well as semi-structured interviews with the schools' management and pedagogical coordination. We found out that, in the pedagogical practice, the evaluation tools focus on the students' written production. Arguments put forward by the participants were internal agreements at school, the number of students per class, the shortage of teacher time and their limited knowledge of assessment instruments.
\end{abstract}

Keywords: Elementary School. Learning assessment. Teaching practice.

\section{RESUMO}

Para compreender a escolha dos instrumentos de avaliação da aprendizagem pelos professores no Ensino Fundamental I, realizou-se uma pesquisa de campo em duas escolas da rede municipal de Aracaju/SE. Após uma análise do projeto político pedagógico de cada escola, verificou-se a percepção e a opinião dos professores por meio de questionários e entrevistas abertas com grupos focais, assim como entrevistas semiestruturadas com a gestão e a coordenação pedagógica. Constatamos que os instrumentos de avaliação da produção escrita do aluno predominam na prática pedagógica. Acordos internos na escola, o número de alunos por turma, a escassez de tempo 
do professor e seu conhecimento limitado sobre instrumentos da avaliação, foram argumentos alegados pelos participantes.

Palavras-chave: Avaliação da aprendizagem. Ensino Fundamental. Prática docente.

\section{RESUMEN}

Para entender la elección de los maestros por los instrumentos de evaluación del aprendizaje, se llevó a cabo una investigación de campo de dos escuelas de la red municipal de Aracaju/SE. Después de un análisis del proyecto político pedagógico de cada escuela, se verificó la percepción y la opinión de los maestros por medio de cuestionarios y entrevistas abiertas colectivas, así como entrevistas semiestructuradas con la gestión y la coordinación pedagógica. Observamos que los instrumentos de evaluación de la producción escrita del alumno predominan en la práctica pedagógica. Acuerdos internos en la escuela, el número de alumnos por clase, la escasez de tiempo del maestro y su conocimiento limitado sobre instrumentos de la evaluación, fueron argumentos presentados por los participantes.

Palabras clave: Evaluación del aprendizaje. Educación Primaria. Práctica docente.

\section{INTRODUÇÃO}

A Lei de Diretrizes e Bases da Educação Nacional (LDB/1996) estabelece no artigo 24, inciso $V$, que a avaliação com perspectiva qualitativa na educação básica deve ser prevalente. Nessa legislação constitui-se que a verificação do rendimento escolar deverá acontecer por meio de uma "avaliação contínua e cumulativa do desempenho do aluno, com prevalência dos aspectos qualitativos sobre os quantitativos e dos resultados ao longo do período sobre os de eventuais provas finais" (Brasil, 1996, grifo nosso).

Uma avaliação contínua pode ocorrer com a subdivisão do ano letivo em unidades de ensino. No entanto, se cada uma dessas unidades termina com uma avaliação pontual, corre-se o risco de que a avaliação do final do ano seja uma simples avaliação cumulativa, que soma as eventuais provas somativas de cada unidade, sem acompanhar os resultados ao longo do período. A avaliação contínua com prevalência em aspectos qualitativos temos particularmente em mente aqui a avaliação formativa com um acompanhamento individual do aluno, mesmo que nessa lei não se use o termo.

Para assegurar um acompanhamento individual ou mais individualizado do desenvolvimento escolar, não é suficiente constatar se o aluno domina, ou não, uma determinada competência. É preciso ter informações sobre o porquê das suas fortalezas e fraquezas no processo de aprendizagem. Uma das características da avaliação formativa é proporcionar um retorno direto (feedback) para o aluno sobre sua aprendizagem.

O aluno precisa, por isso, de um feedback imediato com relação à sua produção. Para o fim da autorregulação da aprendizagem pelo aluno, o feedback conduz o aluno a (re-)conhecer e compreender seus erros/fragilidades e seus acertos/potencialidades. E, ao mesmo tempo, o conduz a compreender como alcançar e melhorar os objetivos de aprendizagem. É a partir do feedback do professor, então, que o aluno, desenha o seu caminho de estudos, formula estratégias de superação de dificuldades e fortalece os seus pontos fortes. O benefício do feedback, por sua vez, depende da qualidade das informações da avaliação.

Para obter tais informações existem diversos instrumentos de avaliação que podem ser usados na prática pedagógica. Provavelmente os mais conhecidos, por serem discutidos em diversas obras, como, por exemplo, a de Haydt (2008) e Depresbiteris \& Tavares (2009), sejam a prova escrita, a prova oral, a tarefa de casa, o seminário, o teste sociométrico e as fichas de observações. Além desses, há também outros instrumentos, inclusive, recentemente investigados em pesquisas empíricas, realizadas no Brasil. 
Encontramos essas pesquisas por meio de um levantamento sistemático ${ }^{1}$, feito entre maio e julho de 2016 e novamente em março de 2019, referente aos anos 2010 até 2018, no Banco de Teses e Dissertações da CAPES e na Biblioteca Digital Brasileira de Teses e Dissertações (BDTD), com as palavras de busca: "avaliação formativa", "feedback do professor" e "feedback do aluno". Em total 15 pesquisas empíricas brasileiras tratam de instrumentos de avaliação.

Apenas listamos aqui esses instrumentos de avaliação, objetos dessas pesquisas encontradas: prova (Conceição, 2018; Arruda, 2015; Costa, 2015; Oliveira, 2014), diário reflexivo (Silva, 2014), portfólio (Conceição, 2018; Carvalho, 2017; Cerminaro, 2013; Bona, 2010), relatório descritivo (Lazari, 2013), diário de estudo (Oliveira, 2015), mapa conceitual (Conceição, 2018; Lopes, 2015), autoavaliação (Conceição, 2018; Braga, 2013; Punhagui, 2012; Lameira, 2012) e webquest e jogos digitais (Perez, 2015). A listagem desses exemplos apenas tem o intuito de mostrar a diversidade de instrumentos existentes.

Essa diversidade é útil para permitir uma diversificação de instrumentos de avaliação na prática pedagógica, pois ela favorece, conforme Haydt (2008), uma avaliação formativa no sentido de ampliar o grau e a qualidade das informações sobre o desenvolvimento do aluno e, consequentemente, identificar com maior precisão as suas fragilidades e potencialidades. No entanto, pesquisas ainda revelam a predominância da avaliação somativa no contexto escolar (Silva, 2016; Silva, 2015; Oliveira, 2014; Lopes, 2012).

O fato de que ainda se observa o predomínio da avaliação somativa em escolas, apesar da LDB ter estabelecido a demanda de uma avaliação contínua, cumulativa e com perspectiva qualitativa, motivou-nos a buscar compreender a escolha dos professores pelo uso de determinados instrumentos de avaliação. Perguntamos, por isso, em duas escolas da rede municipal de ensino de Aracaju/SE, os tipos de instrumentos usados pelos professores, as razões e/ou motivos de escolha e as concepções de avaliação aplicadas no contexto escolar.

\section{ESCOLHAS E PROCEDIMENTOS METODOLÓGICOS}

Realizamos a pesquisa de campo em duas escolas para maior consistência nas conclusões (Yin, 2010). As escolas fazem parte do grupo de instituições de Ensino Fundamental I da rede municipal de Aracaju. Focalizamos no Ensino Fundamental I porque ele é ministrado por pedagogos (exceto da educação física), em vez de professores de matérias escolares específicas.

As duas instituições foram escolhidas por apresentar o maior crescimento no índice de Desenvolvimento da Educação Básica (IDEB), desde 2005.0 critério da escolha explica-se pela presunção de que essas escolas talvez tenham realizado um desenvolvimento organizacional que contribuiu na melhoria dos resultados do processo de ensino-aprendizagem. Suspeitamos também que essa evolução do IDEB tenha sido influenciada, entre outros, pela forma como ocorre a avaliação da aprendizagem. Ao escolhermos as duas escolas pelo IDEB, esperamos contribuir com descrições de práticas de avaliação para posteriormente pesquisar por melhores práticas (best practices).

Foi solicitado, em dezembro de 2017, o termo de consentimento na Secretaria Municipal da Educação de Aracaju para que a pesquisa pudesse ser realizada nessas duas instituições. Elas são denominadas aqui de Escola A e Escola B para garantir o seu sigilo. As escolas estão localizadas na zona urbana do município. Atualmente a Escola A conta com 16 professores e a Escola B com 26. Para manter o sigilo das informações dos professores eles são denominados com siglas e usamos a expressão professor(a) quando se refere a uma pessoa.

Em um primeiro momento, analisamos o conceito da avaliação por meio da análise documental do Projeto Político Pedagógico (PPP) das duas escolas. Com referência ao resultado dessa análise, elaboramos um questionário com perguntas fechadas e o aplicamos ao corpo docente

\footnotetext{
${ }^{1}$ Maiores informações sobre o resultado desse levantamento se encontram em Schmitz et al. (2017).
} 
das duas instituições em dezembro de 2017. A participação dos professores era voluntária. Responderam ao questionário 12 professores da Escola A e 24 professores da Escola B. Devido ao número de participantes e análise dos dados predominantemente somatória, optamos por transferir os dados quantitativos em uma tabela do Excel.

Depois de analisar os resultados do questionário, realizamos entrevistas com grupos focais de professores. A participação nessa entrevista também foi voluntária. No início da entrevista, apresentamos um glossário com os instrumentos de avaliação do questionário para aprofundar a discussão a respeito. A entrevista foi gravada e transcrita conforme o sistema de transcrição, indicado em Preti (1999), analisada por pares do grupo de pesquisadores participantes e posteriormente discutida pelo grupo todo. Além disso, mantivemos um diário de campo no qual foram feitas anotações das três pesquisadoras presentes. Os professores receberam crachás com siglas (P1, P2, P3, ...) para identificar suas falas.

A primeira entrevista ocorreu na Escola A, em janeiro de 2018, com a participação de nove professores que dividimos em dois grupos, sendo um composto por cinco professores (P1/A... P5/A) e o outro por quatro (P6/A ... P9/A). Optamos por essa divisão antes da realização da entrevista porque um número menor de participantes aumenta a oportunidade de cada um se pronunciar. $\mathrm{Na}$ Escola B, entrevistamos, em maio de 2018, cinco professores (P1/B ... P5/B) que concordaram em participar dessa etapa da pesquisa.

Após a análise desses dados, realizamos entrevistas semiestruturadas com as pessoas responsáveis pela coordenação pedagógica das escolas para aprofundar as questões sobre o uso dos instrumentos de avaliação. Essas entrevistas ocorreram, em ambas as escolas, em maio de 2018. $\mathrm{Na}$ Escola $\mathrm{A}$, a pessoa responsável pela gestão também se ofereceu para participar de uma entrevista individual. Nesse caso, usamos o mesmo instrumento para entrevista.

\section{RESULTADOS}

Na análise documental do Projeto Político Pedagógico (PPP) da Escola A, constatamos que a avaliação do aluno não é discutida. No PPP da Escola B, a avaliação é tratada como um processo contínuo no qual se aproveita todos os momentos das atividades escolares como parte desse processo avaliativo. No contexto da abordagem da inclusão de alunos com deficiência são apontados explicitamente o portfólio e a observação, mas a respeito dos demais alunos não se trata, no documento analisado, do uso de instrumentos ou métodos de avaliação.

Nas entrevistas conduzidas posteriormente a análise documental e a aplicação do questionário, aparece nas falas dos professores a sua compreensão da avaliação. Em ambas as escolas houve professores que entendem avaliação analogamente com a função de um termômetro da aprendizagem dos alunos. O(A) professor(a) P5/A falou, por exemplo, que a “...avaliação na verdade é como se fosse um termômetro para... verificar quando a gente tem que puxar um pouco mais de cada aluno." (P5/A). Na Escola B, os professores P1/B e P2/B também mencionaram essa função da avaliação. $O(A)$ professor(a) P1/B comentou que "...a prova escrita...é um termômetro para a gente poder fazer a avaliação daquela criança..." (P1/B).

\section{Instrumentos escolhidos pelos professores}

Notamos que, apesar do PPP de cada escola participante não, ou pouco, nortear as escolhas a respeito da avaliação e orientar a favor de algum instrumento avaliativo, os professores parecem optar mais pelo uso de instrumentos da produção escrita. Isso se revelou nas respostas dos professores no questionário em que perguntamos quais dos instrumentos listados, eles costumam utilizar para avaliar os seus alunos, como mostra a tabela 1. Usa-se, conforme todos os professores, mais instrumentos de avaliação da produção escrita do que da avaliação oral, e mais instrumentos de avaliação oral do que do comportamento do aluno. 
No que diz respeito aos instrumentos para a avaliação da produção escrita, mais da metade dos professores informou usar a tarefa de classe, tarefa de casa e provas escritas. Portfólios e mapas conceituais, assim se confirmou na análise das respostas, ainda são pouco usados. A respeito da avaliação da produção oral, a prova oral foi apontada como a mais utilizada. Em ambas as escolas, menos da metade dos professores confirmaram o seu uso. E a avaliação do comportamento do aluno parece ser mais recorrida por meio da ficha de verificação. Além disso, os professores informaram que fazem os alunos praticar também a autoavaliação e a avaliação mútua. A tabela 1 mostra uma vista de relance. Os instrumentos que habitualmente são usados por mais de dois terços do corpo docente são marcados com a cor verde, aqueles que são usados por um a dois terços com a cor amarela e os que são usados por até um terço com a cor vermelha. Usamos as cores do semáforo para ilustrar visivelmente para quais dos instrumentos há uma necessidade de reflexão coletiva.

Tabela 1. Instrumentos que os professores costumam usar.

\begin{tabular}{|c|c|c|c|c|c|c|}
\hline \multirow{2}{*}{$\begin{array}{c}\text { Avaliação da } \\
\text { produção }\end{array}$} & \multirow[b]{2}{*}{ Instrumento } & \multirow{2}{*}{$\begin{array}{l}\text { Total de } 36 \\
\text { professores }\end{array}$} & \multirow{2}{*}{$\begin{array}{l}\text { № dos } 12 \\
\text { professores } \\
\text { da Escola A }\end{array}$} & \multirow{2}{*}{$\begin{array}{l}\text { № dos } 24 \\
\text { professores } \\
\text { da Escola B }\end{array}$} & \multicolumn{2}{|c|}{ Missing data } \\
\hline & & & & & $\begin{array}{c}\text { Escola } \\
\text { A }\end{array}$ & $\begin{array}{c}\text { Escola } \\
\text { B }\end{array}$ \\
\hline \multirow{5}{*}{ Escrita } & Tarefa de classe & & & & 0 & 1 \\
\hline & Tarefa de casa & & & & 0 & 0 \\
\hline & Prova escrita & & & & 0 & 1 \\
\hline & Mapa conceitual & & & & 2 & 4 \\
\hline & Portfólio & & & & 0 & 3 \\
\hline \multirow{2}{*}{ Oral } & Seminário & & & & 2 & 1 \\
\hline & Prova oral & & & & 0 & 2 \\
\hline \multirow{5}{*}{$\begin{array}{c}\text { Comporta- } \\
\text { Mental }\end{array}$} & Ficha de anedotário & & & & 0 & 5 \\
\hline & Ficha de cumulativa & & & & 0 & 4 \\
\hline & Ficha de verificação & & & & 0 & 4 \\
\hline & Ficha de escala de classificação & & & & 0 & 3 \\
\hline & Teste sociométrico & & & & 0 & 6 \\
\hline \multirow{2}{*}{$\begin{array}{l}\text { Próprio } \\
\text { aluno }\end{array}$} & Revisão por pares & & & & 0 & 2 \\
\hline & Autoavaliação & & & & 1 & 3 \\
\hline
\end{tabular}

Fonte: Elaboração das autoras com base nos resultados dos questionários aplicados na pesquisa de campo, 2018.

São marcados em verde aqueles instrumentos que foram indicados por $>2 / 3$ dos professores; amarelo aqueles usados de $1 / 3$ a $2 / 3$ do corpo docente e vermelho aqueles que $<1 / 3$ deles aplica.

O motivo do uso com predominância de um (ou alguns) determinado(s) instrumento(s) pode ser pelo fato de desconhecer instrumentos alternativos. Notamos pela análise dos resultados dos questionários que há instrumentos de avaliação desconhecidos pelos professores participantes. Sobretudo para a avaliação do comportamento do aluno, constamos que os instrumentos são menos conhecidos, mas, em total, não há nenhum instrumento que foi desconhecido por mais do que dois terços do corpo docente.

No entanto, despertou a nossa curiosidade o fato que há professores que não usam instrumentos apesar de ter conhecimento deles e que há professores que já usaram alguns instrumentos, mas não os utilizam mais, como mostra a tabela 2. Entre os instrumentos conhecidos, mas não usados (ou não mais usados) também se encontramos o portfólio e o seminário. 
Tabela 2. Instrumentos que os professores conhecem, mas não utilizam (mais).

\begin{tabular}{|c|c|c|c|c|c|c|}
\hline \multirow{2}{*}{$\begin{array}{c}\text { Avaliação da } \\
\text { produção }\end{array}$} & \multirow[b]{2}{*}{ Instrumento } & \multirow{2}{*}{$\begin{array}{l}\text { Total de } 36 \\
\text { professores }\end{array}$} & \multirow{2}{*}{$\begin{array}{c}\text { № dos } 12 \\
\text { professores } \\
\text { da Escola A }\end{array}$} & \multirow{2}{*}{$\begin{array}{c}\text { № dos } 24 \\
\text { professores } \\
\text { da Escola B }\end{array}$} & \multicolumn{2}{|c|}{ Missing data } \\
\hline & & & & & $\begin{array}{c}\text { Escola } \\
\text { A }\end{array}$ & $\begin{array}{c}\text { Escola } \\
\text { B }\end{array}$ \\
\hline \multirow{5}{*}{ Escrita } & Tarefa de classe & & & & 0 & 1 \\
\hline & Tarefa de casa & & & & 0 & 0 \\
\hline & Prova escrita & & & & 0 & 1 \\
\hline & Mapa conceitual & & & & 2 & 4 \\
\hline & Portfólio & & & & 0 & 3 \\
\hline \multirow{2}{*}{ Oral } & Seminário & & & & 2 & 1 \\
\hline & Prova oral & & & & 0 & 2 \\
\hline \multirow{5}{*}{$\begin{array}{c}\text { Comporta- } \\
\text { mental }\end{array}$} & Ficha de anedotário & & & & 0 & 5 \\
\hline & Ficha de cumulativa & & & & 0 & 4 \\
\hline & Ficha de verificação & & & & 0 & 4 \\
\hline & Ficha de escala de classificação & & & & 0 & 3 \\
\hline & Teste sociométrico & & & & 0 & 6 \\
\hline \multirow{2}{*}{$\begin{array}{l}\text { Próprio } \\
\text { aluno }\end{array}$} & Revisão por pares & & & & 0 & 2 \\
\hline & Autoavaliação & & & & 1 & 3 \\
\hline
\end{tabular}

Fonte: Elaboração das autoras com base nos resultados dos questionários aplicados na pesquisa de campo, 2018.

São marcados em verde aqueles que $<1 / 3$ do corpo docente não usam; amarelo aqueles que de $1 / 3$ a $2 / 3$ dos professores não usam e vermelho aqueles instrumentos que $>2 / 3$ dos professores não usam.

\section{Razões e motivos da escolha de determinados instrumentos}

As razões que impulsionam a escolha do instrumento para avaliar o aluno foram levantadas por meio das entrevistas com os grupos focais de professores nas escolas. Os professores da Escola A disseram que eles têm autonomia para decidir o instrumento utilizado. "A escola sempre orientou que a nota nunca fosse toda de uma prova escrita, mas que fosse feito outros tipos de avaliação. Foi orientação da escola, mas não é cobrado do professor." (P9/A). Isso foi confirmado pela coordenação pedagógica e a gestão informou que se indica instrumentos avaliativos, mas cabe ao professor decidir aquele adequado para a sua turma.

...a gente conversa nas reuniões pedagógicas de que forma a gente pode avaliar o aluno...e como nossos professores a maioria já são experientes... já sabem que não é só prova... sabem que têm outras formas de você avaliar... Então assim a gente dá uma sugestão...às vezes pode ser uma sugestão acolhida...ou não...vai ficar também às vezes à critério do professor...porque cada professor conhece sua turma nem toda turma pode ser avaliada da mesma forma né?. (Gestão da Escola A).

Um fato interessante é que os dois grupos entrevistados começaram a argumentar sobre a prova escrita. Isso é curioso porque o questionário tinha revelado que a prova é um dos instrumentos mais usados pelos professores, mas também há a tarefa de classe e a tarefa de casa que eles costumam usar. Na entrevista, no entanto, a conversa se concentrou na prova escrita.

Perguntamos aos professores, então, porque alguns instrumentos são mais utilizados e outros não. Os professores P5/A e P9/A do segundo grupo focal da Escola A abordaram a possibilidade de perceber as dificuldades dos alunos em alguma área do conhecimento ou em determinado conceito com a prova escrita e que ela pode indicar se o conteúdo não ficou bem explicado. Também os professores P7/A e P9/A desse mesmo grupo mencionaram que utilizam a prova por ser uma prática natural. "É uma coisa que acontece naturalmente...não é uma opção...na minha visão naturalmente os professores usam esse instrumento com os alunos." (P7/A). Novamente nos surpreendeu que nenhum deles se referiram à tarefa de casa, sendo ela, conforme Nogueira (2002), uma prática que se foi naturalizando nas escolas. 
E consideramos interessante que a entrevista da Escola $B$ também se iniciou com falas a respeito da prova escrita. $\mathrm{O}(\mathrm{A})$ professor(a) P2/B mencionou que a utiliza porque "...ela é tipo uma exigência da instituição..." (P2/B). A exigência foi confirmada pela coordenação pedagógica da Escola B. A escolha dos instrumentos de avaliação parece aqui acontecer de forma diferente da Escola A. A pessoa responsável pela coordenação pedagógica informou que ficou estabelecido com os professores que oito pontos da nota final dos alunos seriam reservados para prova escrita e dois pontos para os demais instrumentos. A justificativa dessa sugestão é que os professores "...têm uma autonomia muito boa, entendeu?...mas aí eu tentei amarrar um pouco mais essa questão da pontuação." (Coordenação pedagógica da Escola B).

No decorrer das respectivas entrevistas de grupo, perguntamos aos professores da Escola $A$ e da Escola B pelos motivos do uso a favor dos outros instrumentos da avaliação da produção escrita. Os professores relataram que utilizam a tarefa de casa e a tarefa de classe para que eles próprios acompanhem se o aluno entendeu o conteúdo e para que os alunos assimilem o conteúdo estudado. É importante “...uma tarefa relacionada àquele conteúdo para ver se realmente o aluno entendeu..." (P2/A).

Semelhante a esses argumentos para a tarefa de casa, foram os argumentos apresentados pelos professores (P1/A e P2/A e P2/B) para a prova oral, em específico, e a avaliação da oralidade do aluno, em geral. Apesar desses argumentos, o(a) professor(a) P6/A esclareceu que não usa a prova oral, pois não há como comprovar a nota do aluno: “...como eu vou mostrar aos pais a nota que o aluno tirou...já que não tem a parte escrita...vai que o aluno tira 2 na prova oral e os pais perguntam...como?...quem é que vai provar que ele tirou?..." (P6/A). A respeito da avaliação por meio do seminário, o(a) professor(a) P2/B informou que usa porque consegue fazer as interferências de forma imediata e reforçar o que já foi estudado pela turma. Houve também o pronunciamento do(a) professor(a) P6/A que não usa o seminário devido à idade inadequada dos alunos. No que diz respeito à avaliação comportamental nenhum dos professores comentou, nesse momento da conversa, um instrumento.

Os instrumentos da avaliação do comportamento listados no questionário são desconhecidos por uns ou conhecidos, mas não (mais) utilizados por outros professores. Por isso, perguntamos se os professores utilizam outros instrumentos para registrar os resultados da avaliação do comportamento ou as habilidades e as dificuldades dos alunos, além dos listados no questionário.

$\mathrm{O}(\mathrm{A})$ professor(a) P4/A revelou que utiliza uma ficha de comportamento para comunicar aos pais possíveis ocorrências com o filho, “...porque aí de repente a gente chama o pai e diz...tá acontecendo isso e eu registrei aqui...às vezes é um caso de agressão e violência...a gente chama a família e assina que ficou ciente daquela situação." (P4/A). Os professores P8/A e P9/A usam as suas próprias agendas. "Eu anoto, mas não tem uma ficha não...padrão...não tenho uma forma...eu vou anotando na agenda no dia..." (P9/A).

Notamos que nem todos os professores que conhecem os instrumentos para avaliação comportamento do aluno os aplicam de forma planejada, conforme os objetivos de aprendizagem, e os preenchem de forma sistemática. Parece-nos mais compreendido como um livro de ocorrências para lembrar e registrar os acontecimentos na sala de aula.

Percebemos também a falta de sistematização no que diz respeito a outros registros de avaliação. $\mathrm{O}(\mathrm{A})$ professor(a) P5/A disse: “...eu tenho uma tabela com os nomes dos alunos e a partir do momento que eu pego as atividades de casa eu coloco lá um mais ou um menos...aí eu tenho condições de que quando chega o final do mês saber quem fez tantas atividades e quem não fez" (P5/A). Essa estratégia é parecida com a do(a) professor(a) P1/B que registra e recompensa por meio de estrelinhas quem realizou as tarefas solicitadas por ele(a) e "...a maioria da sala traz...um ou outro que não traz e ele sabe...se ele não trazer ele vai receber um menos...se ele trouxer dois dias ele não recebe a estrelinha na sexta-feira"(P1/B). E o(a) professor(a) P4/A faz “... registros 
individuais de alguns porque tem coisas que você precisa aplicar para um, mas não precisa mais para outro porque ele já avançou, ele já conseguiu alcançar aquela meta..." (P4/A). É com esse auxílio do registro que ele(a) consegue, apesar de certa dificuldade em relação ao uso do registro individual devido à quantidade de alunos na turma, realizar atividades com "...aquele grupinho que está precisando mais...é um jogo...juntando sílabas...um jogo da memória...uma coisa assim porque reforça mais aquilo que ele está precisando." (P4/A). Também outro(a) professor(a) mencionou que, ao fazer registros, dá atenção diferenciada aqueles alunos que “...não estão alfabetizados..." (P5/B).

Nessas falas, entendemos a tentativa dos professores de individualizar o atendimento dentro da sala de aula, mas sentimos falta tanto de uma sistematização dos dados levantados, quanto de uma diversificação de instrumentos para assegurar um acompanhamento adequado de cada aluno. Por isso, perguntamos também aos professores diretamente sobre a diversificação dos instrumentos usados para a avaliação da aprendizagem.

$\mathrm{O}(\mathrm{A})$ professor(a) P1/B disse que é difícil utilizar diversos instrumentos de avaliação devido à quantidade de alunos que compõe uma turma e, além disso, argumentou que a maioria dos professores trabalham em mais de uma escola.

Infelizmente a gente tem uma carência muito grande de usar outros instrumentos...gente tenta fazer o que a gente possui e se virar nos trinta... então tem hora que você vai por aquilo mais institucional...a prova escrita... porque a gente tem que ter nota no final da unidade, né? (P1/B)

Concebemos uso da expressão "mais institucional" usada pelo(a) professor(a) nesse contexto específico porque, como vimos, em ambas as escolas a prova escrita é um dos instrumentos de avaliação mais utilizados e, inclusive, na Escola B ficou estabelecido o uso desse recurso para a maior parte da composição da nota do aluno.

Contudo, nem todos os professores, assim se revelou na entrevista, acham o uso da prova escrita e, no caso da Escola B, com peso predefinido adequado, tendo em vista o nível de maturidade e aprendizado dos alunos. Por isso, o(a) professor(a) P3/B informou que busca “...avaliar também oral porque tem aquelas crianças que as vezes não conseguem escrever o que aprenderam e são melhores falando e a gente tenta avaliar das diversas formas para poder atingir a todos." (P3/B).

Vale ainda mencionar, a experiência dos professores com o uso de instrumentos de autoavaliação ou avaliação mútua dos alunos. $O(A)$ professor(a) P6/A informou que já utilizou a revisão por pares por meio de ditado, mas não utiliza mais, pois nos momentos das correções os alunos apagavam as respostas dos outros colegas e isso acabava impossibilitando a avaliação.

Eu faço o ditado e para ajudar na correção um pega o caderno do outro e corrige...só que às vezes dá uma confusão porque sempre aparece um com muito erro e o outro com tudo certo, aí eu tenho que pegar para corrigir e ver se realmente o outro escreveu certo, sem contar que eles apagam (P6/A).

Chamou também a nossa atenção que, na fala dos professores, a avaliação é associada por vezes à atribuição de uma nota.

\section{DISCUSSÃO}

A analogia entre a avaliação escolar e a mensuração de temperatura, feita por alguns professores das escolas participantes, também já foi usada por autores, como, por exemplo, Sant'Anna (2014). A nosso ver, cabe ressaltar que essa analogia se refere a avaliação escolar, mas não expressa suficientemente a essência da avaliação formativa da aprendizagem. Medindo o desempenho do aluno, em um primeiro momento, como aponta Sant'Anna (2014), obtemos informações sobre o estado alcançado do desempenho. Isso, sim, é comparável analogamente com o uso de um termômetro que se usa para medir a temperatura corporal. O termômetro indica se a 
temperatura está na faixa normal ou se há uma reação corporal anormal. No entanto, o termômetro não dá informação sobre o porquê da temperatura alta ou baixa. Para melhorar a temperatura do corpo há de se saber a causa do estado corporal. Analogamente não é suficiente, para melhorar a aprendizagem, medir se o objetivo de ensino foi alcançado ou não. Se não for alcançado, identificouse a existência de um problema referente ao processo de ensino-aprendizagem (ou ao próprio processo de avaliação), mas não se revela qual. A analogia da avaliação com um termômetro, desta forma, não pode ser um indício para uma concepção de avaliação formativa dos professores das escolas participantes. Identificar os alunos com dificuldades de aprendizagem não é suficiente. Percebemos, no entanto, uma concepção formativa da avaliação, até certo ponto, na descrição dos professores das suas tentativas de ajudar, de forma diferenciada, os alunos com dificuldades ou deficiências na aprendizagem.

Neste contexto, é compreensível que a escolha de instrumentos de avaliação há de acontecer sob perspectiva do seu potencial de fornecer informações que possam servir para melhoria da aprendizagem.

Dependendo da qualidade do instrumento pode-se obter informações sobre o desempenho do aluno e, ao mesmo tempo, sobre o caminho do raciocínio aplicado. No que diz respeito a avaliação da competência de leitura, por exemplo, existem testes de identificação de palavras. No entanto, esses nem sempre garantem poder distinguir se o aluno sabe, efetivamente, ler as palavras ou se, devido ao seu conhecimento prévio, conseguiu dar as respostas corretas. Contudo, também há testes que indicam os processos cognitivos de forma melhor. No Stolperwörtertest de Backhaus ${ }^{2}$ (Schneider \& Lindauer, 2007), o aluno precisa retirar a palavra que não cabe corretamente na frase durante a leitura. Esse teste é considerado mais adequado para representar os processos que ocorrem quando o aluno lê em silêncio. Nesse sentido, a depender da qualidade do instrumento ele pode fornecer informações que revelem para o professor a razão do erro do aluno.

E se o instrumento fornece informações úteis para o aluno, depende da qualidade do instrumento, mas também da qualidade da correção e da revisão pelo professor. Se a correção não se restringe apenas à verificação de erros e acertos, mas está sendo acompanhada com indicações de estratégias sobre como melhorar e superar suas fraquezas, a avaliação favorece melhoria da aprendizagem do aluno e a construção do seu conceito de autoeficácia.

Seria, a nosso ver, uma subestimação dar preferência à prova escrita apenas para obter notas ou para obter comprovações diante de terceiros. Ela pode também servir, a depender do seu uso, para uma avaliação formativa. Definir a prova escrita como instrumento (predominante ou principal) na composição da nota do aluno, como está acontecendo em uma das escolas participantes dessa pesquisa, torna ainda mais necessária a conscientização do corpo docente sobre seu uso adequado, sobretudo, a respeito da revisão das respostas dos alunos.

Concordamos com Oliveira (2014) que considera imprescindível devolver, pelo menos, as questões da prova comentadas para que os alunos reflitam e tenham um feedback de forma individualizada. E complementamos, quanto mais imediato a prova revisada seja devolvida ao aluno, maior o possível impacto no autorreconhecimento do aluno sobre seu processo de aprendizagem. Ademais, há de se refletir sobre a necessidade de corrigir todos os erros e observar como corrigi-los. A depender do objetivo de aprendizagem pode-se focalizar em um determinado aspecto trabalhado nas unidades do ensino a que a prova se refere. Assim, erros dentro desse aspecto são comentados, enquanto os demais podem ser apenas marcados ou até, se o professor considerar melhor para o autoconceito do aluno, ser desconsiderados. A revisão devolvida aos alunos que o sobrecarrega de informações negativas poderá levá-lo a um conceito negativo de sua autoeficácia. Esses aspectos, no entanto, não se restringem à prova escrita. Eles podem ser um dos pontos a serem considerados no uso de outros instrumentos.

\footnotetext{
2 Trata-se de um teste no qual o aluno precisa identificar aquela palavra que o faz tropeçar. Exemplo: Eu livro sei ler bem. Veja sobre esse tipo de teste também: Metze (2006).
} 
A tarefa de casa e de classe, por exemplo, só podem cumprir a função da avaliação formativa se tiver o devido feedback. No caso específico da tarefa de casa, ainda vale alertar, como outros autores já fizeram (Soares \& Boas, 2011; Schmitz et al., 2016), que o apoio ou a interferência externa que os alunos talvez tenham obtido de terceiros, poderá distorcer a compreensão do professor sobre o erro cometido na produção, ou pior, sobre uma produção alterada dos erros anteriormente cometidos. Isso pode prejudicar a avaliação formativa.

Concordamos com Conceição (2018) que a tarefa de casa pode ajudar o aluno a desenvolver autonomia para monitorar e gerir seu próprio processo de aprendizagem. Aprender abrange também dominar estratégias de aprendizagem, como não desistir diante de erros marcados e críticas colocadas pelo professor e mostrar resiliência na busca por estratégias de soluções das suas próprias dificuldades. No entanto, adicionamos que essas vantagens só podem acontecer quando o professor concebe a tarefa de casa como um instrumento em prol da avaliação formativa.

Em geral, podemos dizer: é imprescindível reconhecer que, para usar a avaliação como um estímulo individual de aprendizagem, há de se preceder uma avaliação diagnóstica, um acompanhamento sistemático para cada aluno e, consequentemente, um registro sistemático para mostrar ao professor o desenvolvimento das competências e habilidades do aluno. Assim também aponta Perrenoud (1999).

E uma diversificação no uso de instrumentos, conforme Haydt (2008), abre possibilidades para obter um maior grau de informação. O aluno que apresenta dificuldade de manifestar seu conhecimento e sua competência por meio de um determinado instrumento de avaliação pode expressá-lo por meio de outro. Essa necessidade de ofertar aos alunos diversos meios de expressar a sua aprendizagem foi mencionada também na entrevista com os grupos focais. A avaliação oral, assim explicou um(a) professor(a), é uma oportunidade para os alunos que ainda não se expressam bem na escrita. Além disso, a diversificação de instrumentos por meio do uso de instrumentos como a prova oral, seminário, mapa conceitual, entre outros, também permitem esclarecimentos sobre as respostas dadas pelo aluno, o que possibilita compreender o seu raciocínio e indicar estratégias para melhorar a sua aprendizagem.

A conversa entre o professor e o aluno sobre as suas respostas estimula o aluno a se envolver, em uma metarreflexão, na sua própria aprendizagem e no seu processo de tomada de decisão sobre como melhorar sua aprendizagem - já desde o Ensino Fundamental I. Por isso, consideramos úteis também para os alunos mais jovens, instrumentos de avaliação como o seminário por meio do qual eles podem ser estimulados a pesquisar e apresentar os resultados oralmente com o apoio de meios e mídias adequadas a sua idade. A observação de um dos professores que desistiu de usá-lo devido a imaturidade dos alunos, leva-nos a recomendar justamente o contrário. A dificuldade observada no comportamento dos alunos é, a nosso ver, um momento para refletir sobre a aprendizagem e estimular o aprender a aprender.

Nas entrevistas com os grupos focais perguntamos também sobre a possibilidade de permitir a participação dos alunos na decisão sobre como será avaliada sua produção e na busca por estratégias de aprendizagem para superar suas dificuldades particulares. Revelou-se que essa possibilidade nunca foi pensada, em nenhuma das duas escolas. A possibilidade dos alunos escolherem, em cada unidade do ano letivo, entre mais de uma forma de avaliação, para demonstrar seu conhecimento e suas habilidades, seria, a nosso ver, uma oportunidade de, não só aumentar a corresponsabilidade do aluno, como também fazê-lo refletir sobre o processo da avaliação, ou seja, assumir também sobre a avaliação numa metaperspectiva. Poder-se-ia, além da prova escrita, oferecer outros instrumentos de avaliação, representando diferentes focos (produção escrita, oral, comportamental e avaliação pelo próprio aluno). O aluno, por exemplo, poderia optar para cada unidade um instrumento, desde que, no final de cada semestre, abrangesse todas as quatro formas de produção de conhecimento. 
A ideia de envolver os alunos na decisão a respeito da avaliação, inclusive sobre os critérios da avaliação preestabelecidos, interessou aos professores do grupo um da escola A que contaram que não tinham o costume de passar explicitamente essas informações para os alunos, mas, assim confirmaram, sentiram-se incentivados a repensar na prática pedagógica. Essa curiosidade e o ânimo de experimentar algo novo, expressados pelos professores da Escola $A$, ajudarão a superar o receio de não aplicar determinados instrumentos devido à idade do aluno.

Concordamos com Haydt (2008) que a idade tampouco seria um motivo de abrir mão da autoavaliação. Se houver dificuldades do aluno se autoavaliar, o professor pode e deve orientá-lo, compreendendo isso como parte do processo de ensino. Dessa forma, os alunos desenvolverão progressivamente a habilidade de autorreflexão e autoanálise. Os obstáculos associados à idade dos alunos, relatados por um(a) professor(a) na entrevista, a nosso ver, revela a necessidade de maiores esclarecimentos sobre vantagens e desvantagens de instrumentos de avaliação e seu uso adaptado à faixa etária dos alunos.

Além dos obstáculos relatados, outras respostas dadas no questionário pelos professores e seus comentários na entrevista, parecem-nos indicar que se haja necessidade de sensibilização sobre a importância de diferenciação no uso dos instrumentos de avaliação. Sobretudo há de se ter o discernimento de diferenciá-los para que eles se complementem.

O potencial da avaliação depende da capacitação do corpo docente. Por isso, também perguntamos sobre a formação continuada dos professores a respeito da avaliação da aprendizagem. A coordenação e gestão da Escola A e a coordenação da Escola B comentaram sobre as reuniões de horas de estudo em parceira com a Secretaria Municipal de Educação (SEMED), quando, entre outros temas da educação também se discute a avaliação. No entanto, os professores criticaram, na entrevista do segundo grupo da Escola A, que essas reuniões apresentam somente uma abordagem. "Quando você faz um curso hoje em dia (na secretaria) tem uma abordagem, mas ela não é suficiente né?" (P9/A).

\section{CONCLUSÃO}

Cabe ao órgão responsável da rede mantenedora ofertar constantemente cursos de atualização do know how dos professores da sua rede a respeito da avaliação da aprendizagem. A nosso ver, cursos ou oficinas também devem ser ofertados in situ com assistência prática para os professores, no sentido de atender a demanda específica de cada comunidade escolar. Sugerimos isso porque as razões de não avaliar com uma diversidade de instrumentos, invocadas pelos professores dessa pesquisa, são, além da imaturidade devido à idade dos alunos, a possibilidade de comprovação diante de terceiros, a quantidade de alunos por turma e a falta de tempo por trabalhar em mais de uma escola. Então, não são razões que apenas indicam a falta de conhecimento pedagógico, são também condições de natureza estruturais e organizacional. Se um curso de formação continuada transmite o conhecimento sobre avaliação e instrumentos, os professores ainda se veem diante das condições desfavoráveis e podem justificar, por conseguinte, a não operacionalização daquilo que foi aprendido no evento da formação continuada. Recomendamos também à coordenação pedagógica, ofertar regularmente encontros entre professores e demais educadores para refletir coletivamente acerca da avaliação, sobretudo acerca da avaliação formativa. Esses encontros teriam o objetivo de discutir sobre a diversificação dos instrumentos avaliativos aplicados, a sistematização dos resultados, para que sejam transparentes e acessíveis para todos envolvidos, e modos de transmitir um feedback individual para cada aluno no que diz respeito ao seu trajeto de aprendizagem.

Organizar esse tipo de formação na própria escola tem a vantagem de poder partir do conhecimento dos professores e da coordenação pedagógica sobre o perfil do alunado e as condições socioculturais da comunidade. A nosso ver, se pode prevenir que a oferta da formação continuada permaneça apenas em um nível de abordagem, como os professores participantes dessa 
pesquisa criticaram, pois é a necessidade do contexto escolar e a demanda específica de cada instituição de ensino que conduz o conteúdo da capacitação in situ.

Não queremos aqui subestimar ou ignorar o quadro das condições de trabalho específicas relatadas pelos professores, mas entendemos que essas condições não podem servir como justificativa para deixar de avaliar o aluno de maneira formativa. Ao contrário, são motivos para procurar por inovações pedagógicas. Cabe à coordenação pedagógica sondar e sistematizar os obstáculos percebidos pelos professores para desenhar as mudanças necessárias para organização do trabalho pedagógico em prol de uma avaliação formativa.

Possíveis mudanças foram, por exemplo, descritas por Oliveira (2014), tais como reservar um tempo no início ou final da aula para, enquanto entrega a prova, conversar individualmente ou em grupos sobre como melhorar em determinados assuntos ou habilidades. Também se pode inspirar na busca por inovações, não apenas na literatura específica nacional, mas também em outras escolas ou no exterior.

Existem experiências como o Schülersprechtag ${ }^{3}$ na Alemanha, que oferta um tempo dedicado plenamente ao feedback dado ao aluno. Em um dia especial, cada aluno conversa com seu professor da turma ou com professores das matérias sobre seu desempenho e seu comportamento social. Partindo da autoavaliação do próprio aluno o professor dá um feedback, que inclui dicas para o desenvolvimento de competências e capacidades. O professor e o aluno (junto com os pais) realizam um acordo ou contrato de educação [original: Erziehungsverträge] sobre o que e como será alcançado em determinado prazo (Schultebraucks-Burgkart, 2008). Inspirado nisso, se poderia pensar em organizar um dia no qual os alunos possam obter maiores informações sobre o resultado da avaliação e sobre o que fazer para melhorar o desempenho, em conversas individuais com seus professores após cada unidade do ano escolar. Ideias como essas podem ser inspiradoras para pensar em estratégias próprias para diminuir ou até prevenir obstáculos para uma avaliação formativa.

As estratégias escolhidas pela escola deverão ser inseridas no seu PPP, porque, como constatamos, o PPP de ambas as escolas participantes pouco ou nada aborda explicitamente sobre a avaliação da aprendizagem do aluno, apesar deste documento escolar nortear o processo de ensino-aprendizagem. Consideramos essa lacuna no PPP como uma oportunidade perdida para conscientizar não apenas os profissionais da escola sobre a função e possíveis formas da avaliação, mas também os pais e os responsáveis pelos alunos.

$E$, finalmente, queremos redirecionar algumas considerações finais à formação inicial dos futuros professores. Há de se ter, nas Instituições de Ensino Superior, um olhar crítico sobre o quanto a(s) disciplina(s) relacionada(s) à avaliação educacional ensinam não só teoricamente, mas também com vista à prática pedagógica, à elaboração de instrumentos e ao registro dos resultados em prol de um monitoramento mais individualizado.

Em futuras pesquisas pretendemos sistematizar a oferta de disciplinas a respeito da avaliação na formação de pedagogos, por um lado, e, por outro lado, aprofundar a análise mais detalhada das correções e feedback dados pelos professores sobre os instrumentos de avaliação, como também uma análise mais aprofundada sobre a construção desses instrumentos. 0 último foco é tema de uma pesquisa em andamento na rede municipal de Aracaju, cujos resultados estão sendo esperados para o início do ano 2021.

Contribuições dos Autores: Schmitz, H.: concepção e desenho, aquisição de dados, análise e interpretação dos dados, redação do artigo, revisão crítica relevante do conteúdo intelectual; Almeida, T. G. S.: concepção e desenho, aquisição de dados, análise e interpretação dos dados, redação do artigo, revisão crítica relevante do conteúdo intelectual; Souza,

\footnotetext{
${ }^{3}$ No Schülersprechtag, cada aluno conversa com seu professor da turma ou das matérias sobre seu desempenho e seu comportamento social, partindo de uma auto avaliação do próprio aluno para qual o professor dá um feedback, que inclui dicas para o desenvolvimento de competências e capacidades.
} 
B. N.: concepção e desenho, aquisição de dados, análise e interpretação dos dados, redação do artigo, revisão crítica relevante do conteúdo intelectual. Todas as autoras leram e aprovaram a versão final do manuscrito.

Aprovação Ética: Não aplicável.

Agradecimentos: Não aplicável.

\section{REFERÊNCIAS}

Arruda, J. (2015). O uso das avaliações escritas de Matemática no 9o ano do Ensino Fundamental em escolas públicas do Gama-DF. Dissertação de Mestrado, Universidade de Brasília, Brasília, Brasil.

Bona, A. S. (2010). Portfólio de Matemática: um instrumento de análise do processo de aprendizagem. Dissertação de Mestrado, Universidade Federal do Rio Grande do Sul. Porto Alegre, Brasil.

Braga, M. S. C. (2013). (Auto) avaliação da aprendizagem: uma investigação sobre suas possibilidades nos anos iniciais do ensino Fundamental. Dissertação de Mestrado, Universidade Federal do Estado do Rio de Janeiro, Rio de Janeiro, Brasil.

Brasil (1996). Lei no 9.394, de 20 de dezembro de 1996. Estabelece as diretrizes e bases da educação nacional. Diário oficial da República Federativa de Brasil, Brasília, DF: DOU.

Carvalho, Â. P. (2017). Construção de portfólio: uma proposta para a avaliação da aprendizagem no Ensino de Química na EJA. Dissertação de Mestrado, Universidade de Brasília, Brasília, Brasil.

Cerminaro, M. C. (2013). Possibilidades no uso de portfólios na aprendizagem da língua materna na escola. Dissertação de Mestrado, Universidade Federal de São Carlos, São Paulo, Brasil.

Conceição, J. L. M. (2018). Instrumentos de avaliação formativa: panorama e percepção docente. 92 f. Dissertação de Mestrado, Universidade Federal de Sergipe, São Cristóvão, Brasil.

Costa, I. L. (2015). As concepções e práticas avaliativas em Matemática de um grupo de professores do 5o ano do ensino fundamental e suas relações com a Prova Brasil. Dissertação de Mestrado, Universidade de Brasília, Brasília, Brasil.

Depresbiteris, L. \& Tavares, M. R. (2009). Diversificar é preciso...: instrumentos e técnicas de avaliação da aprendizagem. São Paulo: Senac.

Haydt, R. C. C. (2008). Avaliação do processo ensino-aprendizagem. São Paulo: Ática.

Lameira, R. S. (2012). Instrumentos formativos e regulação no processo de ensino/aprendizagem da escrita. Dissertação de Mestrado, Universidade Federal do Pará, Belém, Brasil.

Lazari, C. B. S. (2013). Avaliação na educação infantil: concepção de professoras do município de Cáceres expressa nos relatórios descritivos de avaliação. Dissertação de Mestrado, Universidade do Estado de Mato Grosso, Cáceres, Brasil.

Lopes, L. F. (2015). O uso de MC em uma abordagem socio-interacionista no ensino de Física. Dissertação de Mestrado, Universidade Estadual Paulista, São Paulo, Brasil.

Lopes, M. T. L. (2012). Representações sociais de avaliação da aprendizagem por pais e professores de alunos dos anos iniciais do ensino fundamental. Dissertação de Mestrado, Universidade Estácio de Sá, Rio de Janeiro, Brasil.

Metze, W. Stolperwörter-Lesetest. (2006). In: Grundschulverband, A. G. V. (2006). Lesekompetenz: ein Lese und Arbeitsbuch des Grundschulverbands. Frankfurt am Main: novuprint, p. 164-170.

Nogueira, M. G. (2002). Tarefa de casa: uma violência consentida?. São Paulo: Edições Loyola.

Oliveira, M. F. K. (2015). Autorregulação: o uso de diários de estudo por alunos do 5o ano do ensino fundamental. Dissertação de Mestrado, Pontifícia Universidade Católica de Campinas, São Paulo, Brasil.

Oliveira, W. M. (2014). “Devolutiva” e avaliação formativa. Dissertação de Mestrado, Universidade Nove de Julho, São Paulo, Brasil.

Perez, L. A. (2015). Um estudo sobre o uso de avaliações apoiadas pelas tecnologias. Dissertação de Mestrado, Universidade de São Paulo, São Paulo, Brasil.

Perrenoud, P. (1999). Avaliação: da excelência à regulação das aprendizagens- entre duas lógicas. Porto Alegre: Artmed.

Preti, D. (1999). O discurso oral oculto. São Paulo: Humanitas Publicações. 
Punhagui, G. C. (2012). Autoavaliação na aprendizagem de língua inglesa: limites e possibilidades para a autorregulação. Dissertação de Mestrado, Universidade Estadual de Londrina, Londrina, Brasil.

Sant'Anna, I. M. (2014). Por que avaliar? como avaliar?: critérios e instrumentos. Petrópolis: Vozes.

Schmitz, H., Almeida, T. G. S., Souza, B. N. (2017). O uso da avaliação formativa: uma revisão quantitativa da produção científica brasileira (2010-2015). Anais do 10 Encontro Internacional de Formação de Professores, Aracaju, UNIT, v. 10. p. 1-14.

Schmitz, H., Santos, D. V., Cruz, D. M. S. (2016). A tarefa de casa e seu uso na prática pedagógica: Uma revisão de literatura. Anais do VII Encontro Sergipano de Educação Básica e I Seminário dos Institutos Colégios e Escolas de Aplicação - Regional Nordeste, São Cristóvão.

Schneider, H. \& Lindauer, T. (2007). Lesekompetenz ermitteln: Tests. In: Bertschi-kaufmann, A. (2007). Lesekompetenz, Leseleistung, Leseförderung: Grundlagen, Modelle und Materialien. Seelze-Velber: Kallmeyer Verlag; Zug: Klett, p. 126-140.

Schultebraucks-Burgkart, G. (2008). Verträge machen Schule: Erziehungsverträge zwischen Eltern, Kindern und Lehrkräften.Grundschule, 40(10), 46-48.

Silva, A. M. (2016). Geografia no ensino médio: práticas de avaliação em escolas estaduais de Juiz de Fora - MG. Dissertação de Mestrado, Universidade Federal de Juiz de Fora, Juiz de Fora, Brasil.

Silva, D. M. (2015). Avaliação do professor pelo aluno: o ensino e a prática avaliativa em geografia em escolas públicas municipais de Fortaleza/CE. Tese de Doutorado em Educação, Universidade Federal do Ceará, Fortaleza, Brasil.

Silva, M. A. (2014). Diário reflexivo e avaliação formativa nas aulas de Língua Inglesa da Educação Básica: um estudo de caso. Dissertação de Mestrado, Universidade Federal de Uberlândia, Minas Gerais, Brasil.

Soares, E. R. M. \& Boas, B. M. F. V. (2011). Dever de casa, avaliação e organização do trabalho pedagógico. Anais do IV EDIPE - Encontro Estadual de Didática e Prática de Ensino, Goiânia, PUC, 4.

Yin, R. K. (2010). Estudo de caso: Planejamento e métodos. Porto Alegre: Bookman.

Recebido: 20 de agosto de 2020 | Aceito: 2 de agosto de 2021 | Publicado: 17 de agosto de 2021

This is an Open Access article distributed under the terms of the Creative Commons Attribution License, which permits unrestricted use, distribution, and reproduction in any medium, provided the original work is properly cited. 